\title{
Coaching interno: do discurso gerencialista ao sequestro da subjetividade
}

\author{
Gustavo Henrique Carvalho de Castro ${ }^{1}$ \\ Universidade de Brasília (Brasília, DF, Brasil) \\ Bárbara Novaes Medeiros ${ }^{2}$ \\ Universidade de Brasília (Brasília, DF, Brasil) \\ Cledinaldo Aparecido Dias ${ }^{3}$ \\ Universidade de Brasília (Brasília, DF, Brasil) \\ Marcus Vinicius Soares Siqueira ${ }^{4}$ \\ Universidade de Brasília (Brasília, DF, Brasil)
}

\begin{abstract}
Este artigo analisa como a instrumentalização do coaching pelas organizações, enquanto prática gerencial, propicia a reprodução de preceitos gerencialistas que se alinham ao sequestro da subjetividade do trabalhador. Para tal, efetuaram-se entrevistas semiestruturadas com 11 gestores que conduziam tal intervenção no ambiente de trabalho. A interpretação dos dados fundamenta-se na Análise Crítica do Discurso, textualmente orientada. Embora o coaching no trabalho suscite reflexividade, tal prática encontra-se a serviço do ideal gerencialista, reafirmando o ideário social de culto ao desempenho, que propaga auto (e alta) responsabilização individual. O paradoxo é que a subjetividade hiper solicitada para dar lugar a uma "subjetividade realizadora" - foi representada discursivamente como entrave ao desenvolvimento pessoal, o qual é indissociado de anseios organizacionais. Por fim, discute-se o papel da resistência no bojo do referido processo de intervenção.
\end{abstract}

Palavras-chave: Análise crítica do discurso, Coaching, Psicossociologia crítica.

Internal coaching: from managerial discourse to subjectivity kidnaping

This article analyzes how the instrumentalization of coaching by organizations, as a managerial practice, provides the reproduction of managerial precepts that are in line with the kidnapping of the worker's subjectivity. To this end, semi-structured interviews were carried out with 11 managers who conducted such intervention in the workplace. Data interpretation is based on the textual oriented Critical Discourse Analysis. Although coaching at work raises reflexivity, such pratice is at the service of the managerial ideal, reaffirming the social ideal of performance worship, which propagates individual self (and high) responsibility. The paradox is that subjectivity - hyper-requested to give way to a "fulfilling subjectivity" - was represented discursively as an obstacle to personal development, which is inseparable from organizational concerns. Finally, the role of resistance within the aforementioned intervention is discussed.

Keywords: Critical discourse Analysis, Coaching, Critical psychosociology. 


\section{Introdução}

$\mathrm{O}$ estilo de vida hipermoderno é característico da contemporaneidade e evidencia-se em contradições como a que reforça, para cada indivíduo, o mantra "seja você mesmo", na medida em que também lhe requisita sucesso em variados domínios da vida social (Gaulejac, 2017). Nesse sentido, o coaching, intervenção originalmente empregada no esporte para conduzir à alta performance (Chambefort, 2006; Sarsur \& Parente, 2019), vem se tornando um dos métodos de desenvolvimento pessoal mais populares na atualidade (Oliveira-Silva et al., 2018). Segundo Gaulejac (2017, p. 27), tal processo "não é mais reservado para atletas. Ele está se espalhando em todos os setores da vida social em que a concorrência tornou-se uma norma" e se expressa em áreas como forma física, educação infantil (Chambefort, 2006), carreira, saúde e bem-estar (Cox et al., 2014), vida pessoal (Grant, 2016) e refugiados e minorias (Shoukry \& Cox, 2018).

No contexto organizacional ${ }^{5}$, o coaching é um processo de aprendizagem em torno de determinada demanda, em que interações sistemáticas são realizadas entre o coach (treinador que emprega técnicas de intervenção) e o coachee (aprendiz) (Cox et al., 2014). Nesse contexto, embora a literatura registre uma miríade de aplicações do coaching nas organizações (Blackman et al., 2016), duas delas têm se afirmado sobremaneira: coaching executivo, cujo propósito é desenvolver competências interpessoais e de liderança, sob orientação de especialistas externos; e coaching interno, modalidade em ascensão nas relações laborais, em que um gestor da organização torna-se o coach, treinando empregados (Abel \& Nair, 2015; Grant, 2016; Louis \& Diochon, 2018).

A produção científica sobre coaching interno não é exígua em âmbito funcionalista (Blackman et al., 2016; Campos \& Pinto, 2012). Contudo, a popularização desordenada e equivocada da intervenção aponta para um conjunto de técnicas empregado pelas organizações com base no pop-management (Sarsur \& Parente, 2019; Wood et al., 2011). Trata-se de um processo oriundo de técnicas humanistas ocidentais e da mercantilização de terapias espirituais, que psicologizam os fenômenos organizacionais, dissimulando o controle do indivíduo (Chambefort, 2006; Shoukry \& Cox, 2018).

Nesse sentido, a crítica sobre o processo de coaching nas organizações vem sendo majoritariamente orientada por preocupações com competências ou efetividade (Louis \& Diochon, 2018; Sarsur \& Parente, 2019). Em contraponto, a crítica não funcionalista, que evidencia aspectos ideológicos, restringe-se a análises teórico-documentais (Chambefort, 2006; Salles et al., 2019; Shoukry \& Cox, 2018). Dessa forma, este artigo distancia-se da preocupação funcionalista ou exame conceitual, adotando um enfoque teórico-crítico do coaching.

No ensejo de refletir criticamente sobre tal processo no trabalho, o objetivo é o de analisar como a instrumentalização do coaching pelas organizações, enquanto prática gerencial, propicia a reprodução de preceitos gerencialistas que se alinham ao sequestro da subjetividade do trabalhador. O conceito do sequestro da subjetividade é adotado por possibilitar a interpretação, na dinâmica das relações sociais de trabalho, de uma intenção de se acionar práticas não ditas, mas propagadas e produzidas nas organizações com vistas a criar e gerenciar, a partir de uma forma de controle sutil, cadeias de relacionamentos das quais o indivíduo não consegue se afastar (Faria \& Meneghetti, 2007).

5 A expressão "contexto organizacional" abarca, em linhas gerais, os múltiplos sistemas contemporâneos de organização do trabalho no capitalismo, incluindo instituições públicas, privadas ou não governamentais. $\mathrm{O}$ artigo se alinha ao conceito de "empresa hipermoderna", proposto por Pagès et al. (2006), fazendo referência àquela que requisita superlativamente a subjetividade e utiliza-se de artimanhas gerenciais e mediações para dirimir conflitos sempre iminentes entre capital e trabalho; elite e trabalhador. Ademais, se admite que o "contexto organizacional" nunca é estanque, o que leva o trabalho e suas relações a contínuas mutações, como observado na hipermobilidade do capital (Silver, 2005); na crise financeira de 2008 e na ascensão do capitalismo de plataforma, registrados nas últimas décadas (Braga, 2017). Nesse sentido, não se descartam as repercussões negativas para o trabalho (terceirização, trabalho remoto/trabalho híbrido e uberização/gig economy) que derivam desses marcos e incidem no "contexto organizacional". Porém, para pensar com Linhart (2015), reconhecemos que é após crises como a de 2008 que as empresas capitalistas intensificam sua busca por adesão do indivíduo à cultura e ao sistema produtivo, investindo em políticas de recursos humanos que abusam do "humano" no trabalho, ou seja, da subjetividade. 
Para tal, foram efetuadas 11 entrevistas semiestruturadas com gestores que conduziram o coaching junto aos trabalhadores nas organizações. A interpretação fundamenta-se na Análise Crítica do Discurso (ACD) de Fairclough $(2003,2016)$. A ACD é mobilizada pois articula uma dialética sobre o discurso, tomando-o como constituinte e reflexo de práticas sociais (Salles \& Dellagnelo, 2019). Essa dialética reflete-se em âmbito epistemológico, dado que este estudo se norteia pela Psicossociologia Crítica, cuja abordagem, partindo das asserções da Teoria Crítica, entende processos psíquicos como indissociados dos problemas e fatos sociais (Enriquez, 1997; Gaulejac, 2007, 2017).

\section{Discurso gerencialista e sequestro da subjetividade}

O trabalho na hipermodernidade está permeado por injunções paradoxais, como sugerido por Gaulejac $(2007,2017)$. Tais injunções provocam efeitos na relação que o indivíduo mantém com a empresa, fazendo com que se ampliem espaços de promoção de tecnologias de gestão da subjetividade. Nesse cenário, o poder organizacional encontra-se regido pela ubiquidade do capitalismo financeiro; e a vigilância e a punição do trabalhador não desaparecem, porém, diferentemente da empresa moderna clássica, tornam-se mais sutis. Assim, as organizações produzem e propagam discursos como formas de mediação cada vez mais implícitas, que, amparadas por diretrizes pretensamente neutras, destinam-se ao domínio psicológico (inclusive afetivo) e ideológico-cognitivo do empregado, minando suas resistências, e protegendo assim interesses organizacionais (Béhar, 2019; Enriquez, 1997; Faria \& Meneghetti, 2007; Gaulejac, 2007; Pagès et al., 2006).

Na mediação ideológica, compreende-se, segundo Gaulejac (2007), que a partir da ideologia gerencialista, as intenções do poder organizacional são ocultadas, seja por meio de práticas gerenciais em recursos humanos (Faria \& Meneghetti, 2007), seja por meio do modus operandi do discurso gerencialista, que vincula à linguagem princípios homogeneizadores de condutas, como gestão de si (Tonon \& Grisci, 2015) e meritocracia (Béhar, 2019). Assim, a ideologia gerencialista caracteriza-se como sistema de representação mental por preconizar que as esferas da atividade humana podem e devem ser gerenciadas, com vistas ao sucesso (Gaulejac, 2007; Tonon \& Grisci, 2015). De acordo com Fairclough (2016), a hegemonia, dialeticamente, produz e reforça a dominação em processo no qual influencia e é influenciada por discursos (re)produzidos, que refletem "códigos sociais, regras e convenções, mas também moldam as estruturas sociais” (Salles \& Dellagnelo, 2019, p. 418).

Por conseguinte, a injunção da mediação ideológica com a linguagem afirma-se nos discursos gerencialistas: do executivo bem-sucedido como ícone do sucesso (Siqueira, 2009; Tonon \& Grisci, 2015); veiculados na mídia e imprensa por "gurus" do empreendedorismo e do sucesso (Wood et al., 2011); e que, nas organizações, a partir de práticas gerenciais, incitam ao controle do domínio psicológico com intenção de impossibilitar o questionamento das relações de poder (Enriquez, 1997; Faria \& Meneghetti, 2007). Propaga-se o gosto pelo desafio, o desejo pelo reconhecimento e a responsabilização individual pelos resultados organizacionais, canalizando-se a energia libidinal e a mobilização psíquica em favor da adesão voluntária aos objetivos organizacionais (Enriquez, 1997; Gaulejac, 2007; Pagès et al., 2006).

De outra parte, a mediação psicológica enreda no indivíduo a pulsão de apresentar-se útil para o sistema social, de modo a alienar seus processos para se fazer sujeito (Béhar, 2019; Faria \& Meneghetti, 2007). Pretende-se a homogeneização de comportamentos e o compromisso com a organização, por meio de mediações e promessas de sonhos e desejos, vantagens e benefícios, como recompensas econômicas e simbólicas, que recorrem ao intelecto e ao psiquismo para fortalecer o vínculo empresa-indivíduo (Enriquez, 1997; Gaulejac, 2007; Pagès et al., 2006; Siqueira, 2009).

A subjetividade torna-se, portanto, a instância principal de controle, a fim de que os empregados aliem-se ao projeto de excelência da organização (Enriquez, 1997; Faria \& Meneghetti, 2007; Gaulejac, 2007). É quando ocorre o sequestro da subjetividade, como 
pontuam Faria e Meneghetti (2007), para dizer sobre a forma de atuação da organização para limitar a liberdade de crença e a visão crítica do indivíduo, com intenção de apropriar-se da subjetividade para que ele fique à mercê do que ela produz e propaga. Ao formar percepções e representações que impulsionam o indivíduo agir a favor dos objetivos organizacionais, o sequestro da subjetividade está na ordem do domínio psíquico, emocional e afetivo. Cria-se um "imaginário do logro", como dito por Enriquez (1997, p. 35), através do qual a organização é idealizada como toda poderosa, uma espécie de mãe que protege o indivíduo e tende a conhecer e suprir as suas necessidades ao estabelecer um elo de amor, que nutre os desejos narcísicos de reconhecimento e potência do indivíduo com promessas de realização. Assim, o trabalho ganha uma carga de dependência, aproximando-se, por assim dizer, de um "pacto com o diabo: eu renuncio a mim mesmo"; deixo de me pertencer ... (Pagès et al., 2006, p. 141).

Posto isto, práticas organizacionais destinam-se a chancelar o sistemático controle já exercido sobre o indivíduo, no qual o poder é internalizado subjetivamente (Béhar, 2019; Faria \& Meneghetti, 2007). Disponibiliza-se uma gama de instrumentos que visam ao autogerenciamento dos indivíduos frente às exigências organizacionais, a exemplo do coaching em organizações (Brunel, 2004, 2006; Chambefort, 2006; Gaulejac, 2007). Segundo Brunel (2004, p. 19), técnicas de desenvolvimento pessoal como o coaching operam como "possibilidade de expressão e de realização de si mesmo".

Compreende-se que o discurso pode materializar o processo de sequestro da subjetividade (Faria \& Meneghetti, 2007), pois, se, por um lado, a linguagem proporciona poder para a ideologia gerencialista afirmar-se na esfera mais íntima do trabalhador, por outro, não se pode desconsiderar que práticas como o coaching são, eminentemente, práticas discursivas, ou conversacionais, como reconheceu Grant (2016); e, assim o sendo, são práticas sociais (Fairclough, 2016) de inculcação de crenças e valores que alcançam ao domínio psíquico do indivíduo, com intenção de controlar para produzir, de modo que o trabalhador se sinta pertencente ao capital (Faria \& Meneghetti, 2007).

\section{Controvérsias do coaching em organizações}

Diálogo pautado na retórica socrática dos gregos antigos (Brunel, 2004; Sarsur \& Parente, 2019); carruagem que conduzia pessoas no interior da Europa dos séculos XV e XVI, a qual convencionou-se chamar de coche (Campos \& Pinto, 2012; Cox et al., 2014); ou treinamento difundido no meio esportivo norte-americano a partir das décadas de 1950 e 1960, que popularizou os coaches (treinadores de times) para várias questões da vida humana ocidental, incluindo os negócios (Chambefort, 2006; Oliveira-Silva et al., 2018; Salles et al., 2019). Essas, todas, são hipóteses inconclusas sobre a etimologia do coaching, indicando um processo que, permeado pela controvérsia como fundante, integra-se à gestão organizacional de pessoas, enquanto extensão de intervenções paulatinas dos mentores e dos "gurus" espirituais (Abel \& Nair, 2015; Brunel, 2004; Grant, 2016).

Segundo Salles et al. (2019), o coaching nas organizações tem no seu bojo técnicas de intervenção e práticas discursivas empregadas há pelo menos meio século por gerentes. $\mathrm{O}$ giro da abordagem, do coaching externo para o interno, logra que estes, enquanto coaches internos, sejam capazes de dar vazão às demandas por liderança (Sarsur \& Parente, 2019; Wood et al., 2011), compreendendo aspectos inerentes à cultura organizacional e proporcionando às empresas reduzir custos com especialistas (Abel \& Nair, 2015). Ressalta-se que "um gestor pode aplicar técnicas de coaching, o que não faz dele um coach ... cujo propósito é conduzir o coachee aos seus objetivos individuais" (Salles et al., 2019, p. 3236).

Diante disso, a subjetividade torna-se objeto de desejo sob condução dos "gurus" da alma (Brunel, 2004). Explora-se a capacidade de tomada de decisão em consonância ao investimento no seu potencial. No entanto, o desafio não se restringe ao desempenho de tarefas, mesmo porque o alvo é a mudança de pensamentos - "caminho estratégico para minimizar resistências organizacionais" (Salles et al., 2019, p. 3239). Assim, o processo, segundo Grant (2016), se 
mostra mais do que um treinamento convencional, no qual o trabalhador seria um agente per se sobre as próprias metas a serem alcançadas. Em realidade, a autonomia dá-se em conformidade com o incremento da produtividade, numa parceria constante entre organização e indivíduo.

Salles et al. (2019) indicaram que se emprega uma perspectiva subjetiva em favor de uma objetividade, na qual discursos de coaches na mídia de negócios, por exemplo, reforçam a ideologia gerencialista, abordada por Gaulejac (2007), ao enfatizarem palavras-chave que são combinadas sob duas perspectivas: subjetiva (englobando comportamentos e atitudes, como "felicidade", "prosperidade", "transformação" e "coragem") e objetiva (incluindo técnicas e organização do trabalho, como "foco", "metas", "performance", "alto desempenho" e "resultados").

Isso suscita um processo em que contradições sociais são transpostas para os problemas relacionais, promovendo uma "psicologização" do controle (Brunel, 2004, 2006; Chambefort, 2006; Louis \& Diochon, 2018). Tal asserção encontra sintonia com o ideário neoliberal, que focaliza o indivíduo como unidade social independente e o incita, pelo discurso da meritocracia, a adquirir competências pessoais (Shoukry \& Cox, 2018). A implicação é a de, por vezes, o trabalhador internalizar uma imagem negativa de si, já que passa a ser dele próprio a responsabilidade por se autogerir psicologicamente (Brunel, 2004, 2006; Chambefort, 2006).

Assim, trabalhadores passam a ser alvos de múltiplas intervenções, tendo seus aspectos pessoais constantemente inventariados, como em: sessões periódicas para fazer balanços do desempenho de equipes; metodologias participativas; aconselhamento de carreira; e práticas discursivas como as "perguntas poderosas" e os jargões neurocientíficos, que intentam a aprendizagem pela repetitividade (Abel \& Nair, 2015; Campos \& Pinto, 2012; Grant, 2016; Sarsur \& Parente, 2019).

Para o trabalhador, essa alta incidência de conversações enfatizando desempenho, quando esse nem sempre é alcançado, pode levar ao mal-estar psicológico e ao desengajamento (Gaulejac, 2017; Grant, 2016). Outro aspecto é que a recusa de participação em atividades do coaching pode produzir a imagem negativa de um trabalhador perante os outros, uma vez que o discurso do desenvolvimento pessoal é imperativo (Louis \& Diochon, 2018). Essas conversações, ainda, podem levar a conflitos de interesse, uma vez que a influência do gestor, determinando o caminho a seguir, seria incompatível com a proposta emancipatória do coaching, conforme discutiram Ellinger et al. (2008).

Em face às controvérsias apresentadas, o coaching interno tem se tornado um dispositivo ideológico de mudança organizacional, recorrendo a discursos gerencialistas e somando-se à produção de imprensa sobre aspectos que moldam comportamentos e organizações (Chambefort, 2006; Salles et al., 2019). Assim, pensar no discurso gerencialista sobre coaching interno implica reconhecer que, além da propagação do gerencialismo, busca-se instrumentalizar subjetividades.

\section{Metodologia}

Este estudo foi operacionalizado segundo os procedimentos metodológicos da Análise Crítica do Discurso (ACD) (Fairclough, 2003, 2016). A ACD entende o discurso como prática social, refletindo representações ideológicas a respeito da realidade e empregando dialética entre discurso, texto e prática social, o que oportuniza desvelar aparatos de dominação em estruturas sociais e promover a mudança social (Fairclough, 2016).

Adotou-se como foco do estudo os significados representacional e identificacional dos discursos (Fairclough, 2003), tendo em vista a recorrência desses significados no corpus textual de análise. O significado representacional está relacionado ao modo como os aspectos físico e social do mundo são discursivamente representados pelos atores (Fairclough, 2003). Já o significado identificacional relaciona-se ao conceito de estilo e revela como as pessoas identificam a si e aos outros, bem como o modo como são identificadas por outros (Resende \& Ramalho, 2005). 
Para análise do significado representacional, as categorias transitividade e representação dos atores sociais apresentaram-se como as mais oportunas. Nos textos, a transitividade favorece a identificação dos processos, dos participantes e das circunstâncias em que os fenômenos acontecem, sinalizando associações entre o que é realizado e os papéis atribuídos aos envolvidos (Salles \& Dellagnelo, 2019). A representação dos atores sociais auxilia tanto na identificação de ideologias dissimuladas nos aspectos linguísticos dos textos quanto no entendimento social da relevância de se incluir ou excluir atores sociais (Salles \& Dellagnelo, 2019).

Para o significado identificacional, três categorias apresentaram-se como as mais propícias para a análise. A categoria avaliação analisa as apreciações do interlocutor, mais ou menos explícitas, sobre aspectos do mundo, sobre o que considera desejável ou indesejável (Fairclough, 2003). A categoria modalidade revela o modo "como as pessoas se envolvem quando fazem declarações, perguntas, ofertas ou procuras" (Fairclough, 2003, p. 165), apresentando diferentes formas de comprometimento, envolvimento e responsabilidade do falante com aquilo que ele fala. Considerando que as metáforas encobrem aspectos do que representam (Resende \& Ramalho, 2006), a análise dessa categoria ajudou a explicar o modo de pensar e de agir dos entrevistados, seus sistemas de conhecimento e crença.

O estudo contou com a participação de onze gestores (Quadro 1) que aplicavam o coaching junto a trabalhadores. Seis deles foram acessados por conveniência em curso de especialização em coaching em uma metrópole, enquanto os demais foram selecionados pela técnica snowball sampling (bola de neve) (Flick, 2009), partindo da indicação de profissionais de recursos humanos ou coaching. Esclarece-se que os primeiros seis participantes foram entrevistados presencialmente entre outubro de 2018 e dezembro de 2019. Porém, devido à situação de isolamento social enfrentada no país, como forma de mitigar a disseminação do novo coronavírus (Covid-19), os demais participantes foram entrevistados por videochamada durante o primeiro semestre de 2020.

Quadro 1: Caracterização dos entrevistados

\begin{tabular}{|l|l|l|l|l|}
\hline \multicolumn{1}{|c|}{ ID } & \multicolumn{1}{|c|}{ Gênero } & \multicolumn{1}{c|}{ Formação Superior } & \multicolumn{1}{c|}{ Cargo } & \multicolumn{1}{c|}{ Ramo da Organização } \\
\hline$[G 1]$ & Feminino & Gestão de RH & Gerente Administrativo & Varejo Farmacêutico \\
\hline$[G 2]$ & Masculino & Contabilidade & Coordenador de Área & Construção Civil \\
\hline$[G 3]$ & Feminino & Administração & Supervisor Administrativo & Clínica/Laboratório \\
\hline$[G 4]$ & Masculino & Administração & Gerente de Faturamento & Comércio Internacional \\
\hline$[G 5]$ & Feminino & Psicologia & Supervisor de RH & Varejo Farmacêutico \\
\hline$[G 6]$ & Feminino & Tecnologia da Informação & Supervisor/Auditoria & Seguros e Valores \\
\hline$[G 7]$ & Feminino & Enfermagem & Coordenadora Hospitalar & Saúde \\
\hline$[G 8]$ & Feminino & Administração & Gerente Departamento Pessoal & Consultoria/Assessoria \\
\hline$[G 9]$ & Feminino & Administração & Coordenadora de Área & Indústria Alimentícia \\
\hline$[G 10]$ & Feminino & Gestão Empresarial & Gerente de Projetos & Educação \\
\hline$[G 11]$ & Feminino & Ensino médio completo & Sócia Rede de Franquias & Cosmética \\
\hline
\end{tabular}

Fonte: Elaborado pelos autores.

A seleção dos participantes norteou-se pela seleção intencional. As entrevistas foram realizadas com o auxílio de roteiro de pesquisa semiestruturado, o que flexibilizou outras questões relevantes emergentes no decurso da conversação (Flick, 2009). Esse roteiro contemplou três blocos de questões: (a) identificação dos respondentes; (b) inserção do processo de coaching como prática gerencial na organização; (c) relacionamento entre indivíduo e organização.

As entrevistas foram realizadas mediante consentimento livre e esclarecido dos participantes sobre sua finalidade, garantindo o sigilo dos dados, a gravação em áudio e a utilização do conteúdo para fins de pesquisa. No caso dos participantes entrevistados presencialmente, o Termo de Consentimento Livre e Esclarecido foi obtido antes de cada entrevista efetuada. Já no caso dos entrevistados por videoconferência, procedeu-se ao envio do referido termo com a assinatura do pesquisador principal para seus endereços de correio eletrônico. À medida que se obtinha a devolutiva do documento com a assinatura do 
participante, a entrevista era então agendada e, posteriormente, realizada em sessão síncrona de videoconferência.

Uma vez transcritas as entrevistas, constituiu-se corpus textual, cuja importância não se restringiu a selecionar verbalizações significativas, mas em operar também no pressuposto de que entrevistas são discursos escritos, em que há seleção de palavras dentro de um contexto finito de opções e há representação, na linguagem, do mundo físico e social (Fairclough, 2003, 2016; Salles \& Dellagnelo, 2019). No percurso das análises, foram constituídos três eixos de discussão sobre o coaching interno, em perspectiva crítica, que correspondem às subseções da próxima seção: (a) concepção; (b) técnicas empregadas; (c) resistência ao sequestro da subjetividade.

Por fim, os excertos analisados, dos 11 interlocutores entrevistados (Quadro 1), encontram-se enumerados de [E1] até [E13], de modo que se facilite a identificação do conteúdo de cada verbalização mencionada, seja em momento próximo, seja em momentos posteriores. Ao final de cada excerto, identifica-se a autoria do excerto, o que compreende os códigos [G1] a [G11].

\section{Resultados e discussão}

\section{Concepção}

Definições sobre coaching interno pressupõem que empregados, embora aspirem ao alcance de metas, seriam atores em busca de reconhecimento ou bem-estar (Campos \& Pinto, 2012; Sarsur \& Parente, 2019). Isso os colocaria em um processo habilitador da tomada de decisões em consonância com o potencial pessoal, conferindo maior autonomia e desenvolvimento pessoal (Salles et al., 2019). A identificação do coaching como técnica de desenvolvimento de pessoas adotada por organizações apresenta-se como modo de gestão de si (Gaulejac, 2007).

E1: não é terapia, não é psicologia, hããã não é autoajuda. Coaching ele é um processo que visa a aumentar a performance do indivíduo, engajar, então hããã "onde o indivíduo está hoje e onde ele quer chegar?" O trabalho do coaching é desenvolver esse gap. Então, é engajamento: onde ele está agora, onde ele quer chegar (G10).

Observando a transitividade de E1, nota-se a negação do processo relacional "não é" para descrição do coaching. As articulações discursivas buscam afastar o conceito de outros campos relacionais ("terapia", "psicologia" ou "autoajuda"). A instrumentalização do coaching pode ser observada no processo relacional identificativo "é" seguido, na primeira descrição, pelo vocábulo "processo" e, na segunda, pelo verbo transitivo direto "desenvolver". Essas articulações são reforçadas pelas circunstâncias temporais e espaciais, indicadoras de um movimento do indivíduo em função do lugar onde ele "está", "hoje" e o lugar "onde ele quer chegar". Outra representação é apresentada ao finalizar o discurso, em que o elemento textual conclusivo "então" conduz ao fechamento das ideias, a partir da oração relacional intensiva "é um engajamento". Semanticamente, tal vocábulo alude a um processo de entrega e devoção, participação a partir da colaboração, o que também pode ser definido como "posição ideológica" em relação a alguma causa.

A interdiscursividade é observada em E1 a partir da apropriação do discurso gerencialista e descreve o objetivo "que visa" a ação do coaching. Os vocábulos "performance", "engajar" e "gap" ilustram o modo como as atividades do coaching se realizam. À luz da psicossociologia, as expressões rememoram as articulações de Gaulejac (2007) quanto ao "discurso da insignificância”, um discurso operatório, que constrói uma representação muito parcial e vaga de sentido completo. O vocábulo "gap", oriundo dos discursos do pop-management, nesse contexto, é mobilizado para representar o hiato entre o indivíduo de hoje e aquele vislumbrado (Brunel, 2004). 
E2: A gente pode até ficar conhecendo o histórico para entender o que está acontecendo hoje, mas a gente não volta para tratar o passado. A gente trata do hoje para frente, né? Então onde ELE está hoje e aonde ELE quer chegar (G11).

Em E2, a interlocutora generaliza o discurso por meio da locução pronominal "a gente". Suas articulações vão ao encontro de E1, ao afirmar que o coaching se ocupa da transposição do indivíduo entre "onde ele está" e "aonde ele quer chegar". Ambos os excertos pressupõem o coaching como condutor, o clássico cocheiro, na tradução mais fiel da palavra, que na antiguidade referia-se àquele que transportava as pessoas de um local a outro (Campos \& Pinto, 2012; Sarsur \& Parente, 2019).

No E2, a categoria transitividade, explícita no processo material "tratar", é usada para referenciar o processo do coaching, numa perspectiva temporal, seja no "passado" e no presente "hoje". O processo utilizado sugere a identificação dos sujeitos, submetidos às técnicas do coaching, como "pacientes" de um tratamento. Contudo, verifica-se que o tratamento oferecido despreza a natureza anterior do sujeito, suas vivências, traumas e lembranças, e se concentra numa tentativa de construir um futuro apenas a partir do presente. Desprezar o passado parece uma maneira de amenizar e escapar dos possíveis sofrimentos que acompanham os sujeitos.

E3: Eu não vou consertar o que aconteceu. O que aconteceu está feito. Quais são as habilidades que você tem, o que você traz até aqui e como é que você vai fazer diferente então a partir de agora. Ou, como é que você vai utilizar o aprendizado que você teve a partir de agora para seguir em frente. É dessa forma. Eu não vou consertar nada! (G11).

Na elaboração de E3, G11 não se utiliza da modalização da fala para expressar a sua técnica, utilizando-se do pronome "eu" para afirmar sua posição em relação àquilo que diz. A negação do processo material "não vou consertar" revela a percepção dos trabalhadores como sujeitos defeituosos, o que ratifica o sentido de "tratar", articulado em E2 e assumido agora com a propriedade da fala. Além disso, reforça a pouca importância dada pelo gerente ao passado do sujeito. Nesse sentido, pode-se dizer que o processo de coaching favorece um modo de alienação do sujeito trabalhador, ofertando a este como antídoto travar uma relação gerencial consigo próprio (Louis \& Diochon, 2018) e usando apenas das potencialidades que ele apresenta.

Ao analisar esses aspectos discursivos frente à Psicossociologia Crítica, é possível identificar certo grau de superficialidade do processo de coaching, no que tange à negligência de aspectos da história de vida individual e das particularidades dos sujeitos. Ademais, essa articulação discursiva dissimula a instrumentalização do coaching como recurso para potencializar a produtividade do trabalhador, com fins de atender às necessidades organizacionais.

Em E4, aponta-se que "a gente na empresa, atualmente, tem trabalhado muito esse quesito de melhorar performance do indivíduo, de tornar ele um líder melhor e, assim, agregar resultado na companhia" G2. Nesse excerto, o interlocutor também parte da generalização do discurso por meio da locução pronominal "a gente". O intensificador "muito" é utilizado para representar o esforço do coaching em conduzir o processo de mudança do indivíduo. Em E3, a interdiscursividade também permeia os discursos do mainstream organizacional, em que os vocábulos "performance", "agregar" e "resultados" denotam a fixação pela criação de sujeitos cada vez mais adaptáveis às exigências organizacionais. Mas é a partir do fortalecimento dos laços e da confiança de que a organização se preocupa com o trabalhador que se conquista a incrementação do "resultado na companhia". Essas articulações corroboram Enriquez (1997), Gaulejac (2007), Pàges et al. (2006) e Siqueira (2009), que descrevem a objetificação do sujeito em função da organização.

Embora negado em E1, o coaching interno parece representar um recurso psicológico estratégico, para explorar as limitações dos trabalhadores na promessa de potencializar suas capacidades (Brunel, 2004, 2006; Chambefort, 2006) e realizá-los, numa relação próxima ao "imaginário do logro" (Enriquez, 1997). Um recurso pedagógico de formação que desloca a responsabilidade pelo sucesso do processo para o próprio trabalhador, delegando-lhe a agência 
de mudar a si, considerando a auto (e alta) responsabilização pelos resultados organizacionais (Brunel, 2006; Chambefort, 2006; Gaulejac, 2007; Salles et al., 2019).

E5: Eu costumo trabalhar muito a auto responsabilização, a autoestima e a possibilidade de a pessoa saber enfrentar tudo. Muito da nossa realidade hoje ela é fruto do nosso comportamento, das nossas escolhas, do nosso dia a dia, e é nós que trabalhamos o resultado da nossa realidade. Então, se você quiser um resultado diferente do resultado do que você está vivendo hoje, você tem que mudar até mesmo seus hábitos. Então, eu trabalho muito essa questão: se você quiser um resultado diferente, MUDA, começa a mudar hoje (G7).

Ao se colocar presente em E5, a interlocutora assume alto comprometimento com aquilo que diz, sem fazer modalizações em relações ao que opera as suas atividades. Os processos materiais "eu costumo" e "eu trabalho" evidenciam o modo de intervenção praticado pela gestora, o que é reforçado pelo intensificador "muito". Tal fato denota a insistência da ação de forjar um processo de mudança de comportamento da parte daqueles que se submetem à prática. Por meio do elemento conclusivo "então", seguido de uma relação de causalidade, E5 evidencia que os resultados se condicionam à obrigatoriedade de mudança comportamental, onde "se você quiser um resultado", "tem que mudar". Para evidenciar a intensidade da mudança, essa mudança deve incorporar "até mesmo seus hábitos".

$\mathrm{Na}$ enunciação, verifica-se um processo de transitividade não-verbal ao longo do texto. No primeiro momento, a interlocutora se coloca em primeiro plano, dotada de agência ("eu costumo trabalhar"), para selecionar vocábulos da perspectiva subjetiva, como, por exemplo, "saber enfrentar tudo" - algo que guarda correspondência com "resiliência" (Salles et al., 2019). No segundo momento, a realidade, incorporada a partir da perspectiva subjetiva (Salles et al., 2019), se perfaz como algo passível de mudança pelo próprio indivíduo, apoiada na estratégia argumentativa de agência compreendida de avaliação pelo senso de coletividade ("nós"/"nossa"/"nosso"), indicando que o comportamento de qualquer indivíduo traria consequências em sua realidade. Por fim, novamente chama a si o dever de desenvolvimento da pessoa, mas desloca para o indivíduo a responsabilidade por tal, o que se evidencia pelo uso do pronome "você" ao final.

Assim, opera-se uma contradição, um paradoxo a que se submete o trabalhador: autoestima e resiliência são abandonados ao longo do argumento, privilegiando-se responsabilidade e "resultado", independentemente de circunstâncias contextuais que podem vir a tolher o desenvolvimento. Depreende-se disso que se busca conformidade às normas, confirmando que "a cada indivíduo é devolvida a responsabilidade de seus sucessos e fracassos" (Gaulejac, 2017, p. 27).

\section{Técnicas empregadas}

O coaching interno utiliza-se de instrumentos específicos por meio dos discursos para alcançar a subjetividade do trabalhador. Esses recursos escamoteiam o controle ideológico pelo imperativo da racionalidade, manipulando a subjetividade e alimentando ideais de realização. Induzidos pelo "império" dos números, os sujeitos se enlaçam em modelos de autoavaliação de desempenho.

E6: É um questionário simples onde a pessoa responde como é que ele se vê. E aí tem aproximadamente uns vinte e cinco adjetivos sobre como é que você se vê e como é que você acredita que o outro gostaria que você fosse. E aí ele responde e também manda para outras pessoas. Duas pessoas do âmbito profissional, duas pessoas do âmbito social, que são os amigos, e duas pessoas que são do âmbito familiar. E aí vai dizer o perfil. Se é um perfil dominante, se é um perfil influente, se é um perfil estável ou se é um perfil conforme (G8).

Por meio do processo relacional atributivo "é" e do qualificador "simples", a interlocutora parte de uma avaliação subjetiva do instrumento "questionário", definindo-o como de baixa 
complexidade. Essa articulação subestima qualquer posicionamento científico ou profissional, que explica a natureza complexa da subjetividade, da identidade e do comportamento humano. Algo que, para a gestora, pode ser manipulado apenas por um processo limitado de "vinte e cinco adjetivos" respondidos. Assim, a ação do coaching interno sugere a manipulação do sujeito a partir da identificação do perfil identificado, uma vez que definido "quem é" o sujeito, torna-se "simples" a maneira como se deve jogar com seus desejos, suas fraquezas, suas instabilidades.

Observa-se uma prerrogativa de sequestro da subjetividade por meio da apropriação de técnicas que vinculam diferentes esferas da vida pessoal do sujeito (Faria \& Meneghetti, 2007), levando-os a se entregarem cada vez mais à organização, tendo em vista que a manipulação dos sentidos na ordem psíquica favorece uma ação instrumental voltada à promessa de satisfação e autorrealização do ego (Chambefort, 2006), "através da formação de crenças no trabalho" (Louis \& Diochon, 2018, p. 6).

E7: ... eu semanalmente trago as pessoas com quem eu vejo potencial que pode galgar melhores posições na companhia ou pode realmente multiplicar pra frente de serviço deles. É essa melhoria então: eu semanalmente trago essas pessoas pra conversar, pra mostrar pra eles aonde é que eles acertaram, aonde eles erraram, e juntos ali a gente construir melhor um profissional, ou melhorar realmente a capacidade dele para as entregas pra companhia $(\mathrm{G} 2)$.

Em E7 delineiam-se técnicas do coaching a partir de temporalidade, indicando que, ao menos uma vez por semana, reuniões são empregadas pelos gestores de forma a avaliar o comportamento dos trabalhadores. A partir da transitividade do processo material "trago", seguido do processo mental perceptivo "vejo", o interlocutor insinua capacidade de manipular "as pessoas" que, sob o seu juízo, são avaliadas com "potencial para galgar melhores posições" ou "multiplicar pra frente de serviços". O processo material "construir" revela o modo como o coaching se representa na interação com os sujeitos, um edificador de pessoas melhores. Ademais, pelo emprego da conjunção "ou", o enunciado esconde a conformidade "multiplicar para a frente de serviço deles" e "melhorar a capacidade para entregas", a partir da perspectiva das relações socioprofissionais da empresa (Siqueira, 2009).

No contexto de E7, a escolha lexical "entregas" também reforça o discurso de dominação e manipulação do sujeito, em que as técnicas de intervenção funcionam como recursos para manipular os sujeitos para a doação e devoção à companhia. À luz da Psicossociologia Crítica, confirmam-se as prerrogativas da entrevista-avaliação-conselho, de Pagès et al. (2006), ao mencionar a exploração da subjetividade dos trabalhadores como recurso para ganhar a fidelidade deles, que se "entregam" voluntariamente ao trabalho gerando, consequentemente, o aumento da produtividade organizacional.

Verifica-se que o monitoramento por sessões reforça a idealização das conquistas individuais, instrumentalizando as aspirações profissionais, na qual a organização passa a ser o lugar de realização pessoal (Gaulejac, 2007, 2017; Siqueira, 2009; Tonon \& Grisci, 2015). Nesse sentido, busca-se aferir com rigor o quão próximo o indivíduo está do destino final, desconsiderando-se que a meritocracia preconiza o sucesso apenas para poucos (Béhar, 2019). Ainda, "diversos recursos são utilizados para desenvolver o processo entre coach e coachee, incluindo as chamadas 'perguntas poderosas' (que mobilizam a reflexão do coachee), o uso de instrumentos de avaliação (inventários de personalidade) e o uso de feedback" (Sarsur \& Parente, 2019, p. 129).

E8: ... É fazer perguntas certas ... Então, como exemplo: "o que que aconteceu? Tem alguma situação que você vivenciou e essa situação mexeu muito com você?” E aí você vai cavando as informações. E aí ela traz uma situação. "Como você enxerga isso? Por exemplo, antes desse cenário e pós esse cenário? Quais foram as mudanças que tiveram na sua vida?" Você vai levando ela para o auto entendimento e para entender que ela precisa de algo maior (G10). 
E9: . . . é como você jogar frases chaves, você consegue quebrar aquela apatia, entendeu? Após isso, jogar alguns pensamentos, alguma coisa que faz a pessoa refletir após algum tempo, a ir pra casa ficar pensando sobre aquilo (G1).

$\mathrm{Na}$ linguagem apresentada, pode-se identificar traços da retórica socrática, frequentemente associada à figura do coaching, para mencionar o uso banalizado de perguntas abertas, escuta e reflexão, como mecanismo do autoaprendizado (Brunel, 2004; Sarsur \& Parente, 2019). Em E8, o processo relacional intensivo "é", seguido do processo material "fazer", é usado para caracterizar a eficácia da técnica das "perguntas poderosas", como se verifica na expressão "fazer a pergunta certa". A natureza indutiva da pergunta é modalizada pelo pronome "você", visto que, para mencionar que "vai cavando", o agente não se posiciona na fala, atribuindo a materialidade do ato de cavar ao outro, nesse caso "você". A seleção do vocábulo "cavando" pressupõe aprofundar, sair do superficial, deixando um buraco, que talvez a técnica não esteja apta a cobrir. A representação do vocábulo apresenta-se como um modo passivoinvasivo da subjetividade. Verifica-se que o processo mental cognitivo "entender" é usado para mudar a percepção da realidade, influenciando a consciência.

Ao finalizar a verbalização, observa-se que não é a pessoa que "precisa de algo", mas é o coaching que tende a levá-la a identificar uma necessidade não latente, como observado em "ir cavando". Nesse sentido, evidencia-se a manipulação do sujeito para o despertar de necessidades, que são avaliadas, exclusivamente, pelo coaching como "algo maior", que aparentemente não são delas, mas produzidas pelo coaching interno. No contexto da sociedade da produtividade, onde as pessoas são seduzidas pelas organizações para serem cada vez mais competitivas (Gaulejac, 2007), a técnica apresenta-se como grande aliada, favorecendo a organização a partir da inculcação de valores que podem sequer terem sido cogitados, mas que serão produzidos e propagados por meio dos discursos.

E9 também opera o discurso da invasão da subjetividade por meio da técnica das "perguntas poderosas". Os processos materiais "jogar frases" e "jogar alguns pensamentos" corroboram o processo de "quebrar apatia", funcionando como representação de um modo de adentrar a subjetividade e condicionar o sujeito. A técnica é marcada pela repetitividade, que inaugura no discurso a saturação de uma questão que leva à eufemização do controle (Brunel, 2004). Imersos na dialética texto-prática social ideológica, "perguntas poderosas" e jargões neurocientíficos constituem práticas discursivas de fácil reprodução nas organizações, já consolidados pelo discurso gerencialista do ambiente de negócios (Duarte \& Medeiros, 2019; Salles et al., 2019).

Portanto, num contexto que o aumento da produtividade é requisito para a realização do ego, redesenhar mecanismos de controle, por meio das técnicas utilizadas no coaching, favorece a responsabilização do sujeito pelas suas insuficiências e apresenta-se como meio para controlar subjetividades. Assim, o discurso do coaching interno, embora verse sobre desenvolvimento pessoal do indivíduo, rege-se pela gestão de si. Para tal, acompanha sua trajetória na organização, requerendo, em nível subjetivo, adesão e mobilização psíquica, e afastando a reflexão crítica sobre o contexto.

\section{Resistência ao sequestro da subjetividade}

Embora toda a convicção da funcionalidade das técnicas empregadas pelo coaching interno como recurso operacional de manipulação da subjetividade dos sujeitos, verifica-se que penetrar no domínio psíquico do trabalhador não se apresenta tão simples como os discursos até então apresentados. A resistência dos sujeitos é apresentada como desafio ao domínio da subjetividade, fato que leva os gestores a insistirem no convencimento de que as limitações são meras impotências.

E10: Nem sempre é tão fácil. Você nem sempre tem uma receptividade boa. Quando não tem essa receptividade, você procura entender a pessoa, você tentar quebrar essa barreira, que, muitas vezes, ela é imposta, é uma coisa muito complicada. Você conseguir passar essa barreira, você 
abordar de um modo diferente, para você entender por que que aquela pessoa colocou aquela barreira ... (G1).

Para demostrar a resistência dos sujeitos ao processo de invasão da subjetividade, E10 apresenta-se modalizado pelo uso do pronome "você". A não inclusão direta da interlocutora no discurso, que se daria a partir do uso do pronome "eu", dissimula o modo impositivo do coaching em penetrar a subjetividade e romper a resistência dos sujeitos, apresentada, metaforicamente como "barreira". A metáfora apresenta uma maneira particular de expressar o mundo que a identifica, marcado pela persistência em dar produtividade para o potencial subjetivo dos trabalhadores.

O processo mental desiderativo "tentar" exprime os esforços em penetrar a subjetividade do trabalhador, o que é elucidado no processo material "quebrar essa barreira" que "é imposta". Discursivamente, tal processo, associado à metáfora "barreira" sugere um modo de romper, abrir, rachar a mente do sujeito, de forma a inculcar percepções diferentes daquelas existentes. Observa-se que esse modo de operação do coaching parece vigorar quando o profissional é subjetivamente rejeitado.

As falas sustentam a tentativa de um dos gestores, de forma invasiva, em captar algo na mente dos trabalhadores. Metáforas como "abrir essas mentes" e "esvaziar as mentes" insinuam a tese do sequestro da subjetividade (Faria \& Meneghetti, 2007).

E11: O grande desafio é fazer com que as pessoas compreendam que elas têm capacidade. Tem muitas pessoas que elas são travadas. Elas não sabem o potencial que têm, então você tentar mostrar isso pra ela é, de certa forma, acho que a coisa mais complicada que tem. Fazer ela se sentir especial e se sentir capaz. Tem pessoas que a gente chega hoje, chama pra falar sobre ela, conversar sobre ela. "Olha eu percebo que você tem facilidade de realizar determinada tarefa ou de realmente conduzir uma outra equipe". E a pessoa fala: "eu não me vejo dessa forma". Ela meio que se trava e você abrir essa mente e colocar essas informações é complicado (G2).

E12: Eu sempre falo que garrafa cheia é mais difícil colocar mais coisa dentro, então é necessário que a gente consiga esvaziar essas mentes (G2).

Em consonância com as discussões anteriores, em E11, a categoria avaliação qualifica as resistências dos sujeitos como um "grande desafio", que parece ser superado a partir da imposição do coaching. O processo material "fazer com que as pessoas" expressa a intencionalidade do coaching em forjar a subjetividade, uma forma de persuadir o sujeito em relação à sua compreensão do que é "capacidade". O uso da metáfora "travadas" faz alusão a um sujeito preso, trancado. Tal fato sugere uma maior ligação do sujeito a si mesmo, do que com as proposições do coaching; um modo de ser que se aproxima da resistência em se entregar ao logro da realização exclusiva pelo trabalho. É o fato de serem "travadas" que dificulta o sequestro da subjetividade.

A modalização da fala, por meio do pronome "você", na qual o interlocutor se esquiva daquilo que afirma, parece justificar a agressividade subentendida nos processos verbalizados em "abrir essa mente" e "colocar essas informações". Após a articulação discursiva de que "ela [a pessoa] trava", identifica-se que o processo de "abrir" não conta com a participação do sujeito, visto que esse se encontra "travado", mas parte de uma violação, uma forma de invadir e incutir uma ideia. Insinua-se que não há uma preocupação do coaching com a aceitação ou não do sujeito, mas a obrigatoriedade de provocar uma mudança subjetiva dele, mesmo que não seja o desejo do trabalhador.

Observa-se, ainda, que o investimento do coaching parte da manipulação do ego como tentativa de seduzir por meio do desejo narcísico (Enriquez, 1997). Nesse caso, o processo material "fazer" apela para a fragilidade e carência do sujeito, imputando a possibilidade de que o coaching é capaz de transformar a vida do sujeito e o induzir a "se sentir especial e se sentir capaz". O discurso sugere que ser capaz volta-se, exclusivamente, para o campo da realização profissional, o que fica subentendido nas locuções "facilidade de realizar determinada tarefa" e "conduzir uma outra equipe". Em E12, verifica-se que a metáfora "garrafa cheia" também parece 
aludir à condição de que o sujeito que se submete ao coaching não é vazio ou sem conteúdo. Pelo contrário, o conteúdo que o sujeito apresenta parece não satisfazer à demanda do coaching, tornando excessivamente importante, sinônimo de "necessário", desfazer-se de si, "esvaziar" e dar lugar à inculcação daquilo que é importante não para o trabalhador, mas para o coaching.

É possível que a resistência do sujeito esteja associada aos outros valores que o constituem. Embora a forte pressão para adesão dos sujeitos à lógica produtivista, sempre resta algo de pessoalidade, que insiste em resistir à essa entrega da alma ao diabo, como já diziam Pagès et al. (2006). Há sempre algo subjetivo, que cultua valores diferentes daqueles dos ditames funcionalistas, e que, ao se sentir invadido, o sujeito tenta não se deixar levar.

E13: ... Ah, no meio vai surgir ... o que nós chamamos de uma crença limitante, de que eles não podem, de que eles não conseguem. A gente ajuda eles a enxergarem que eles mesmos estão convocando impedimentos no caminho deles (G9).

O processo existencial "vai surgir" apresenta a resistência como um fenômeno aleatório, que surge sem qualquer justificativa. É algo que aparece e que deve ser manejado. Na fala de G9, o "impedimento" não se apresenta como uma limitação para o coaching, mas como uma deficiência dos trabalhadores, incluídos no discurso de forma indeterminada. São "eles" que "não podem", "não conseguem" e "estão convocando impedimentos". O processo material "ajudar" insinua uma relação de dependência, uma forma de caridade e assistência do coaching ao trabalhador, que não é capaz de enxergar que pode ser mais capaz. Ainda em E13, o sintagma "crença limitante" identifica a visão da interlocutora para uma limitação dos trabalhadores em se "enxergarem" da forma como o coaching os enxerga. O termo pode ser assimilado à linguagem da insignificância, um discurso evasivo, que se fecha em si mesmo e, por meio da complexidade, tenta afastar-se do senso comum (Gaulejac, 2007).

Observa-se que a noção compartilhada de que "o desafio", a "crença limitante" e o "impedimento", verbalizados de forma negativa pelos gestores que conduzem o coaching, são identificados como mecanismos de resistência individual a serem transpostos. Não há dissenso que reflita, por exemplo, que o contexto ou situação é que podem ser os limitadores. Pela modalização das falas os discursos também revelam o afastamento dos gestores da responsabilização pela necessidade de transpor as resistências. $\mathrm{O}$ uso do pronome "você", por exemplo, faz parte de uma transitividade que encobre aspectos negativos do coaching a partir da impessoalidade empregada, atribui as dificuldades àquele que não consegue transpor suas próprias barreiras.

A dualidade entre a concepção negativa da subjetividade ao longo dos processos de coaching e a dinâmica de incitação ao potencial individual rememora mais do que os sistemas de mediação ideológica e psicológica de Pagès et al. (2006); é a tradução do paradoxo hipermoderno, em que subjetividade é representada como entrave ao desenvolvimento individual, ainda que se necessite manipular subjetividades para promover, de modo controverso, a promessa de emancipação pela "subjetividade realizadora".

\section{Considerações finais}

O presente estudo analisou criticamente a instrumentalização do processo de coaching interno pelas organizações, salientando aspectos ideológico-discursivos e de sequestro da subjetividade. Destaca-se que diferentes discursos representam e identificam, paradoxalmente, a subjetividade como entrave ao desenvolvimento individual, de modo que o coaching interno busca promover a "subjetividade realizadora" como único meio de emancipação.

Como mecanismo de apoio e fortalecimento da ideologia gerencialista, o discurso do coaching é marcado por uma lógica contraditória, que busca prescrever o sucesso individual, além de ter o seu uso e significados distorcidos. A contradição é que a emancipação pelo sucesso jamais se daria em condições de exploração que visam a atender centralmente aos interesses neoliberais. 
Com o sequestro da subjetividade, mesmo que não se trate da gestão da subjetividade por inteiro, devido ao papel da resistência, reforçam-se tentativas de moldar controles cada vez mais sutis. Assim, entende-se que a discussão é pertinente, na medida em que desvela como o coaching aproxima-se de uma metodologia que buscaria manter o status quo. Reflexões dessa natureza sugerem que talvez o coaching não seja de todo um equívoco, mas a superficialidade do processo, a subestimação do sujeito e a pouca formação e qualificação é que depreciam os seus propagadores.

O papel do presente estudo foi o de contribuir para uma literatura, de fato, escassa no país, a qual versa sobre coaching interno, pois, na medida em que pode promover reflexões críticas, pode também complementar materiais necessários à formação crítica de estudiosos de psicologia do trabalho e estudos organizacionais. Uma segunda contribuição a se elencar é a de alertar para os riscos da promoção distorcida de práticas e técnicas de aperfeiçoamento pessoal, as quais, entremeadas ao aparato gerencialista, atuam no controle da subjetividade, e distanciam-se do seu propósito principal, que é o de levar à emancipação dos sujeitos. Incentivam-se estudos futuros evidenciando os mecanismos de resistências dos trabalhadores a intervenções como a abordada no presente escrito.

\section{Referências}

Abel, A. L., \& Nair, S.V. (2015). The rise of coaching in organizations. In D. D. J. Riddle, E. R. Hoole, \& E. C. Gullette (Eds.), The center for creative leadership: handbook of coaching in organizations (pp. 5-28). John Wiley $\&$ Sons.

Béhar, A. H. (2019). Meritocracia enquanto ferramenta da ideologia gerencialista na captura da subjetividade e individualização das relações de trabalho: uma reflexão crítica. Organizações $\mathcal{E}$ Sociedade, 26(89), 249-268.

Blackman, A., Moscardo, G., \& Gray, D.E. (2016). Challenges for the theory and practice of business coaching: a systematic review of empirical evidence. Human Resource Development Review, 15 (4), 459-486.

Braga, R. (2017). O golpe parlamentar e o fim da sociedade salarial no Brasil. IdeAs. Idées d'Amériques, 10, 1-6.

Brunel, V. (2004). Les managers de l'âme. La Découverte.

Brunel, V. (2006). Pratiques réflexives et régulation organisationnelle. Communication et Organisation, 28, 17-31.

Campos, T. M., \& Pinto, H. M. N. (2012). Coaching nas organizações: uma revisão bibliográfica. Revista REUNA, 17(2), 15-26. https://revistas.una.br/reuna/article/view/439/482

Chambefort, C. (2006). Coaching: pour la promotion d'une idéologie normative? Communication et Organisation, 28, $1-17$.

Cox, E., Bachkirova, T., \& Clutterbuck, D. (2014). The complete handbook of coaching (2 ${ }^{\mathrm{a}}$ ed.). Sage.

Duarte, M. P. F. C., \& Medeiros, C. R. O. (2019). Pop-Management: 15 anos depois: a incorporação do popmanagement no trabalho de executivos de grandes empresas. Cadernos Ebape.BR, 17(1), 185-198.

Ellinger, A. D., Hamlin, R. G., \& Beattie, R. S. (2008). Behavioural indicators of ineffective managerial coaching. Journal of European Industrial Training, 32 (4), 240-257.

Enriquez, E. (1997). A organização em análise. Vozes.

Fairclough, N. (2003). Analysing discourse: textual analysis for social research. Routledge.

Fairclough, N. (2016). Discurso e mudança social (I. Magalhães, trad., 2ª ed.). EdUnB.

Faria, J. H., \& Meneghetti, F. K. (2007). O sequestro da subjetividade. In Análise crítica das teorias e práticas organizacionais (pp. 45-67). Atlas.

Flick, U. (2009). Introdução à pesquisa qualitativa. Artmed.

Gaulejac, V. (2007). Gestão como doença social: ideologia, poder gerencialista e fragmentação social. Ideias \& Letras.

Gaulejac, V. (2017). Vivre dans une société paradoxante. Nouvelle Revue de Psychosociologie, 2(24), 27-40. 
Grant, A. M. (2016). The third 'generation' of workplace coaching: Creating a culture of quality conversations. Coaching: an International Joumal of Theory, Research and Practice, 10(1), 37-53.

Linhart, D. (2015). La comédie humaine du travail: de la déshumanisation taylorienne à la sur-humanisation managériale. Editions Erès.

Louis, D., \& Diochon, P. F. (2018). The coaching space: a production of power relationships in organizational settings. Organization, 25(6), 710-731.

Oliveira-Silva, L. C., Werneck Leite, C. D. S., Carvalho, P. S. F., dos Anjos, A. C., \& Brandão, H. I. M. (2018). Desvendando o coaching: uma revisão sob a ótica da Psicologia. Psicologia: Ciência e Profissão, 38(2), 363. 377.

Pagès, M., Bonetti, M., Gaulejac, V., \& Descendre, D. (2006). O poder das organizações: a dominação das multinacionais sobre os indivíduos (10 ${ }^{\underline{a}}$ reimpr.). Atlas.

Resende, V. D. M., \& Ramalho, V. (2006). Análise de discurso crítica. Contexto.

Salles, H. K. D., \& Dellagnelo, E. H. L. (2019). A Análise Crítica do Discurso como alternativa teórico-metodológica para os Estudos Organizacionais: um exemplo da análise do significado representacional. Organizações $\mathbb{E}$ Sociedade, 26(90), 414-434.

Salles, W., Vieira, F. O., Souza, M. S., \& Barros, S. R. S. (2019). “O canto do coaching”: uma análise crítica sobre os aspectos discursivos do triunfo ágil difundido no Brasil. Gestão e Sociedade, 13(36), 3231-3260.

Sarsur, A. M., \& Parente, C. (2019). The coaching process seen from the daily (and controversial) perspective of experts and coaches. Revista de Gestão, 26(2), 126-142.

Shoukry, H., \& Cox, E. (2018). Coaching as a social process. Management Learning, 49(4), 413-428.

Silver, B. J. (2005). Forças do trabalho: movimentos de trabalhadores e globalização desde 1870. Boitempo.

Siqueira, M. V. S. (2009). Gestão de pessoas e discurso organizacional: crítica à relação indivíduo-empresa nas organizações contemporâneas. Juruá.

Tonon, L., \& Grisci, C. L. I. (2015). Gestão gerencialista e estilos de vida de executivos. Revista de Administração Mackenzie, 16(1), 15-39.

Wood, T., Tonelli, M. J., \& Cooke, B. (2011). Colonização e neocolonização da gestão de recursos humanos no brasil (1950-2010). Revista de Administração de Empresas, 51(3), 232-243.

Endereço para correspondência gustavo.hc.castro@gmail.com
Recebido em: 24/11/2020

Revisado em: 04/09/2021

Aprovado em: 18/10/2021 